\title{
Highly Selective Detection of Trace Copper(II) Using Bathocuproinesulfonate by Flow-Injection Electrospray Ionization Mass Spectrometry
}

\author{
Masanobu MoRI ${ }^{\dagger}$ Keiko Misawa, and Hideyuki ITABaSHI \\ Graduate School of Science and Technology, Gunma University, 1-5-1 Tenjin-cho, Kiryu, Gunma 376-8515, Japan
}

\begin{abstract}
Trace $\mathrm{Cu}^{2+}$ was detected with high selectivity using specific complexation with bathocuproinesulfonate (BCS) through flow-injection electrospray ionization mass spectrometry (FI-ESI-MS), which separates $\mathrm{Cu}^{2+}$ from coexisting metal ions by forming a $\mathrm{Cu}-\mathrm{BCS}$ complex with a high mass number. Here, only $\left[\mathrm{Cu}^{\mathrm{I}}(\mathrm{BCS})_{2}\right]^{3-}$ was obtained with a high ion count. Its calibration curve was linear from $1.0 \times 10^{-8}$ to $1.0 \times 10^{-5} \mathrm{M}$. This method was applied to determine the $\mathrm{Cu}$-complexing capacities of humic acid solution and river water samples by adding traces of $\mathrm{Cu}^{2+}$.
\end{abstract}

Keywords Electrospray ionization mass spectrometry, flow injection, copper, chelating agent, complexing capacity

(Received September 16, 2014; Accepted October 31, 2014; Published December 10, 2014)

\section{Introduction}

Electrospray ionization mass spectrometry (ESI-MS) is an analytical method that ionizes, and then measures the chemical species in sample solutions under mild conditions. It is mainly applied to the determination of organic species, such as carboxylates or proteins. It has also often been used as an analytical method to measure the speciation of metal complexes, based on their nature..$^{1-4}$

Typically, a heavy metal ion in a water sample that is softly ionized by ESI forms various metal-hydration complexes. ${ }^{5}$ Therefore, the coordination of a target metal ion and a chelating agent can prevent this hydration, and can effectively separate the ion from coexisting-ionic species. For example, several researchers have reported ${ }^{2-4}$ the quantification and speciation of metal complexes with chelating agents, such as ethylenediaminetetraacetate (EDTA) or diethyldithiocarbamate (DDC).

In this study, we attempted to develop a selective and sensitive detection of $\mathrm{Cu}^{2+}$ by ESI-MS with a flow injection (FI-ESI-MS) using a carrier containing a chelating agent, and to use the method to determine the $\mathrm{Cu}$-complexing capacity $(\mathrm{CuCC})$ of ligands in water samples. CuCC refers to the maximum molar quantity of $\mathrm{Cu}^{2+}$ that can coordinate to the mass unit of unspecified ligands (fulvic acid, humic acid) that are dissolved in environmental water. ${ }^{6}$ The $\mathrm{CuCC}$ of an environmental water sample is determined from the inflection point of free $\mathrm{Cu}^{2+}$ concentration in the sample as a function of the total $\mathrm{Cu}^{2+}$ concentration in the sample. Typically, the concentration of ligands, estimated from the total organic carbon (TOC), is extremely low $(<1 \mathrm{ppm})$ in Japanese river water. Consequently, the trace levels of free $\mathrm{Cu}^{2+}\left(<1.0 \times 10^{-6} \mathrm{M}\right)$ must be monitored in order to find an accurate inflection point for the determination of the CuCC. Itabashi et al. used the back-extraction method to

$\dagger$ To whom correspondence should be addressed.

E-mail: mori@gunma-u.ac.jp determine the $\mathrm{CuCC}$ of humic acid dissolved in water, ${ }^{7}$ but this method required the use of complicated procedures. This paper demonstrates that the $\mathrm{CuCC}$ of genuine river water samples could simply be determined by the proposed method using FIESI-MS.

The highly sensitive and selective detection of $\mathrm{Cu}^{2+}$ by FIESI-MS was developed in the following order: firstly, we selected an appropriate chelating agent for the selective detection of $\mathrm{Cu}^{2+}$. We used aromatic chelating agents, such as tetrakis(4carboxyphenyl)porphyrin (TCPP) and tetraphenylporphyrin tetrasulfonate (TPPS), which are water-soluble porphyrins used for the fluorescence detection of metal ions, ${ }^{8,9}$ and bathocuproinesulfonate (BCS), which is a phenanthroline that selectively binds copper ions ${ }^{10}$ (Fig. S1, Supporting Information). We expected that the influence of the matrices in the ESI-MS analysis of $\mathrm{Cu}^{2+}$ should be minimized if $\mathrm{Cu}$-complexes with larger mass numbers were obtained by using a chelating agent of larger molecular mass. Following this, we optimized the probe and curved desolvation line (CDL) voltages that were applied during the ESI-MS for more sensitive detection.

The optimized method was applied to the determination of the $\mathrm{CuCC}$ of a commercial humic acid dissolved in an aqueous solution and of ligands existing in a real river water sample (Watarase River in Gunma Prefecture, Japan).

\section{Experimental}

\section{Reagents and chemicals}

All reagents were of analytical grade and were purchased from Wako Pure Chemical Industries, Ltd. (Osaka, Japan). The water used for reagent dissolution and sample dilution was obtained from an ASK-2DS ultrapure water system (Iwaki Co., Ltd., Tokyo, Japan). Stock solutions of the metals $\left(1.0 \times 10^{-3} \mathrm{M}\right)$ were prepared by dissolving copper(II) acetate monohydrate with an appropriate amount of water. Chelating agents, TCPP, TPPS, and BCS, were purchased from Dojindo Laboratories, Inc. (Kumamoto, Japan), and were diluted to $1.0 \times 10^{-3} \mathrm{M}$ in 
distilled-deionized water (water).

\section{Apparatus}

ESI-MS was performed with a Shimadzu high-performance liquid chromatograph mass spectrometer, LCMS-2010A, which comprises an ion-spray-type interface that promotes ionized gas. The injected sample volume of the sample solution containing $\mathrm{Cu}^{2+}$ was $30 \mu \mathrm{L}$. The length from injector to detector was $50 \mathrm{~cm}(0.13 \mu \mathrm{m}$ i.d.). Using the flow-injection function in the apparatus, the injected sample was mixed with a carrier comprising $1.0 \times 10^{-3} \mathrm{M}$ ammonium acetate and $2.0 \times 10^{-5} \mathrm{M}$ chelating agent $(\mathrm{pH} 4)$ at a flow rate of $0.20 \mathrm{~mL} / \mathrm{min}$. The $\mathrm{pH}$ was selected with referring to a previous report. ${ }^{11} \mathrm{~A} 1.0 \times 10^{-3} \mathrm{M}$ ascorbic acid used as a $\mathrm{Cu}^{2+}$ reductant was added into the carrier with BCS. The analyte was measured in the negative-ion mode. The other experimental conditions were as follows: nebulizer gas (flow rate), $\mathrm{N}_{2}(1.5 \mathrm{~L} / \mathrm{min})$; drying gas (pressure), $\mathrm{N}_{2}$ (0.04 MPa); probe voltage, -5.0 to $0.5 \mathrm{kV}$; CDL voltage, -30 to $0 \mathrm{~V}$; and Q-array voltage, $-50 \mathrm{~V}$. TOCs in a humic aciddissolved solution and a real river water sample solution were determined using a Shimadzu TOC-V (Shimadzu Co., Ltd.).

\section{Influence of coexisting metals}

We added 1000-fold concentrations of $\mathrm{Zn}^{2+}$ and $\mathrm{Cd}^{2+}$ than that of $\mathrm{Cu}^{2+}$ to the tested solution, in order to observe the influence of excess quantities of metals on the formation of the $\mathrm{Cu}-\mathrm{BCS}$ complex. The sample used for evaluating the influence of coexisting metals for the detection of $\mathrm{Cu}^{2+}$ (as a $\mathrm{Cu}-\mathrm{BCS}$ complex) was obtained by mixing $1.0 \times 10^{-5} \mathrm{M}$ copper(II) acetate monohydrate with $1.0 \times 10^{-2} \mathrm{M}$ cadmium(II) acetate dihydrate, or $1.0 \times 10^{-2} \mathrm{M}$ zinc(II) acetate dihydrate. The carrier was a mixture of $1.0 \times 10^{-3} \mathrm{M}$ ammonium acetate, $2.0 \times 10^{-5} \mathrm{M} \mathrm{BCS}$, and $1.0 \times 10^{-3} \mathrm{M}$ ascorbic acid. The other conditions were as described above.

\section{Determination of $\mathrm{CuCC}$}

Each mixture of various concentrations of copper(II) acetate monohydrate $\left(1.0 \times 10^{-7}-2.0 \times 10^{-6}\right)$ was injected with humic acid (TOC: $6.4 \mathrm{mg} / \mathrm{L}$ ) into the FI-ESI-MS. The carrier, consisting of $1.0 \times 10^{-3} \mathrm{M}$ ammonium monohydrate, $6.0 \times$ $10^{-6} \mathrm{M} \mathrm{BCS}$, and $2.0 \times 10^{-6} \mathrm{M}$ ascorbic acid, was mixed with the sample by FI.

For determining the $\mathrm{CuCC}$ of ligands in river water, various concentrations of copper(II) acetate monohydrate $\left(1.0 \times 10^{-8}\right.$ to $2.0 \times 10^{-7} \mathrm{M}$ ) were added to a river water sample filtered by a membrane filter $(0.45 \mu \mathrm{m} \phi)$. The concentrations of the ligands in the river water were estimated from the TOC. The CuCC values was estimated by referring to a report by Itabashi et al. ${ }^{7}$

\section{Results and Discussion}

\section{Influence of the chelating agent}

The ion counts of the main peaks of each FI-ESI-MS spectrum of $\mathrm{Cu}^{2+}\left(1.0 \times 10^{-5} \mathrm{M}\right)$ coordinated with three different chelating agents $\left(2.0 \times 10^{-5} \mathrm{M}\right.$ each $)$ in the negative-ion mode were compared.

Firstly, anionic porphyrins, such as TCPP and TPPS, were employed as $\mathrm{Cu}^{2+}$ chelating agents. The use of TCPP provided the isolated peak of $\left[\mathrm{Cu}\left(\mathrm{H}_{2} \mathrm{TCPP}\right)\right]^{2-}$ at $m / z=425$, and there were no peaks corresponding to free TCPP or other $\mathrm{Cu}$-TCPP complexes (Fig. 1a). This result provided an isolated peak to allow easy identification of the analyte $\mathrm{Cu}^{2+}$, but it had a small ion count. Because a weakly acidic compound TPCC is partially neutralized at $\mathrm{pH} 4-5$, it might conduct the lower ionization

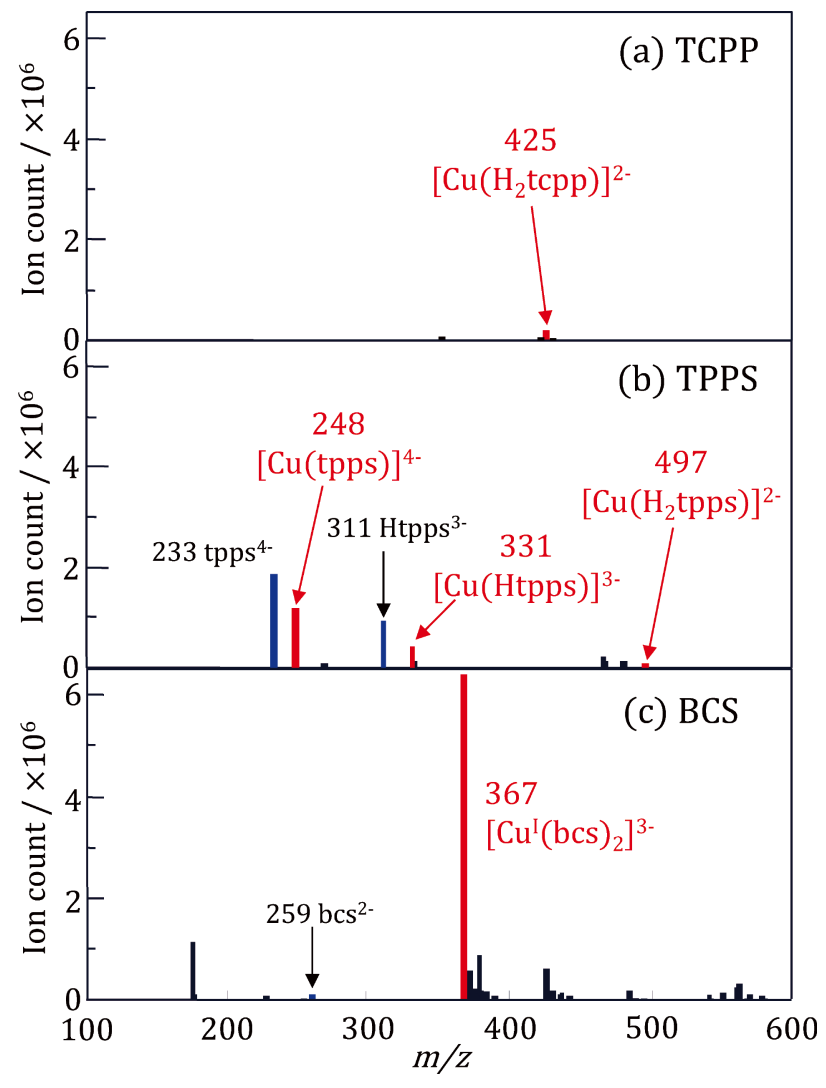

Fig. 1 Mass spectra of $\mathrm{Cu}$-chelating complexes.

Injected sample, $\left[\mathrm{Cu}^{2+}\right]=1.0 \times 10^{-5} \mathrm{M}$; carrier solution, $2.0 \times 10^{-5} \mathrm{M}$ chelating agent in $1.0 \times 10^{-3} \mathrm{M} \mathrm{CH}_{3} \mathrm{COONH}_{4} .1 .0 \times 10^{-4} \mathrm{M}$ ascorbic acid was added into the carrier with only BCS as a chelating agent.

efficiencies in ESI part, though the detail mechanism could not be cleared at this stage.

The use of TPPS provided a high ionization efficiency of $[\mathrm{Cu}(\mathrm{TPPS})]^{4-}$ at $\mathrm{m} / \mathrm{z}=248$, accompanied by trivalent and divalent species at $\mathrm{m} / z=331$ and 497 , respectively (Fig. 1b). This would be possible to determine how many functional groups were coordinated to copper from the spectra. However, the peaks of the $\mathrm{Cu}$-TPPS complexes detected at $\mathrm{m} / \mathrm{z}=248$ and 331 overlapped with those from the spectrum of $\mathrm{Zn}$-TPPS (Fig. S2, Supporting Information). In that of Zn-BCS, the peaks between $\mathrm{m} / \mathrm{z}=300$ and 400 appeared, but they were not detected with the peak at $m / z=367$ that originated from $\left[\mathrm{Cu}^{\mathrm{I}}(\mathrm{bcs})_{2}\right]^{3-}$.

The use of BCS afforded a trivalent anionic species only; that is, $\left[\mathrm{Cu}^{\mathrm{I}}(\mathrm{BCS})_{2}\right]^{3-}$ (Fig. 1c). Ideally, if monovalent and divalent anionic species could be simultaneously detected, this method could be used for the speciation of $\mathrm{Cu}-\mathrm{BCS}$ complexes. However, this method, using BCS, is very selective for $\mathrm{Cu}^{+}$, and the complexation of BCS to other tested metal ions $\left(\mathrm{Fe}^{3+}, \mathrm{Al}^{3+}\right.$, $\mathrm{Zn}^{2+}, \mathrm{Cd}^{2+}$ ) did not occur (data not shown). Additionally, the sensitivity for $\left[\mathrm{Cu}^{\mathrm{I}}(\mathrm{BCS})_{2}\right]^{3-}$ was much higher than that of the $\mathrm{Cu}$-TCPP and $\mathrm{Cu}$-TPPS complexes.

\section{Optimization of the probe and CDL voltages}

Next, we optimized the probe and CDL voltages to enhance the sensitivity for $\left[\mathrm{Cu}^{\mathrm{I}}(\mathrm{BCS})_{2}\right]^{3-}$.

The probe voltage is the voltage applied to the capillary tip of the ESI interface, and it is the ionization source for the conversion of the sample into charged droplets when passing through the capillary. Figure $2 \mathrm{a}$ shows changes in the ion count 


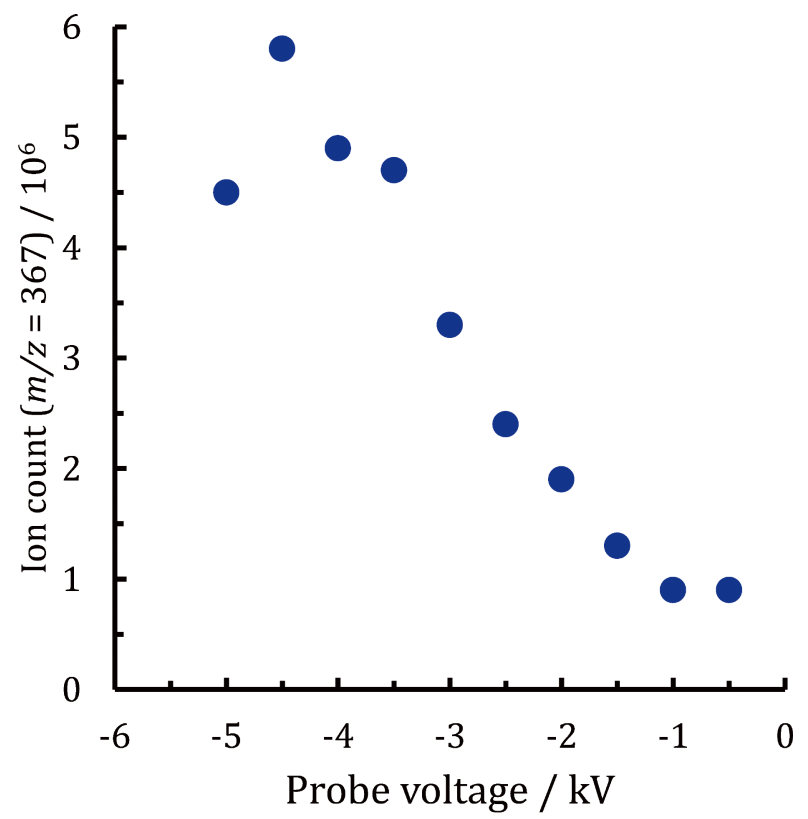

maximum ion count was obtained at $-25 \mathrm{kV}$. The ion count decreased when applying $-30 \mathrm{kV}$ because a portion of the analyte $\mathrm{Cu}-\mathrm{BCS}$ complex might be removed with large droplets. Accordingly, the optimal CDL voltage was $-25 \mathrm{kV}$.

\section{Analytical performances}

Using the optimized conditions described above, the calibration curve of $\mathrm{Cu}^{2+}$ was created from variations in the ion count of $\left[\mathrm{Cu}^{\mathrm{I}}(\mathrm{BCS})_{2}\right]^{3-}(\mathrm{m} / \mathrm{z}=367)$ as a function of the concentration of $\mathrm{Cu}^{2+}$ injected. The calibration curve was linear in the range of $1.0 \times 10^{-8}$ to $1.0 \times 10^{-5} \mathrm{M}$ with a good correlation coefficient $\left(r^{2}=0.9985\right)$ (Fig. S3, Supporting Information).

The detection limit (DL) of $\mathrm{Cu}^{2+}$ as $\left[\mathrm{Cu}^{\mathrm{I}}(\mathrm{BCS})_{2}\right]^{3-}$ at a signalto-noise ratio of 3 was $3.5 \times 10^{-9} \mathrm{M}$. This value is approximately 1000 -fold lower than that of bare $\mathrm{Cu}^{2+}\left(3.2 \times 10^{-6} \mathrm{M}\right)$ detected by the FI-ESI-MS without any chelating agents. In addition, when this DL was compared to several previous reports on the ESI-MS of $\mathrm{Cu}^{2+}$, it was found to be almost equal to or lower than the reported values. For example, the DL is $9.4 \times 10^{-9} \mathrm{M}$ for $\mathrm{Cu}-\mathrm{DDC}\left[\mathrm{Cu}(\mathrm{DDCH})^{+}\right],{ }^{4}$ and $6.0 \times 10^{-9} \mathrm{M}$ for $\mathrm{Cu}-\mathrm{EDTA}$ $\left[\mathrm{Cu}(\mathrm{HEDTA})^{-}\right]^{2}$

Next, the effect of coexisting heavy metal ions, $\mathrm{Zn}^{2+}$ and $\mathrm{Cd}^{2+}$, was examined. A solution containing a 1000-times higher concentration of coexisting metal than that of $\mathrm{Cu}^{2+}$ was injected into the FI-ESI-MS. Only the $\mathrm{Cu}$-BCS complex was detected, with no coexisting metal-BCS complexes evident.

\section{$\mathrm{CuCC}$ of humic acid and ligands in river water}

To demonstrate the application of this study, we attempted to determine the $\mathrm{CuCC}$ of a humic acid solution and a Watarase River water.

As shown in Fig. 3, the ion counts hardly increased when injecting the humic acid solution with $\mathrm{Cu}^{2+}$ solutions ranging from $1.0 \times 10^{-7} \mathrm{M}$ to $7.0 \times 10^{-7} \mathrm{M}$, but rapidly increased when higher concentrations than $7.0 \times 10^{-7} \mathrm{M}$ were injected. The inflection point, estimated from the intersection of the two approximations in Fig. 3, was $6.8 \times 10^{-7} \mathrm{M}$. Consequently, the $\mathrm{CuCC}$ of the humic acid solution obtained from the inflection point with a varying ion count was $1.1 \times 10^{-4} \mathrm{~mol} / \mathrm{g}$. This value means that a mass unit of the humic acid can coordinate $\mathrm{Cu}^{2+}$ up to $1.1 \times 10^{-4} \mathrm{~mol}$, and almost equal to the values $\left(1.0 \times 10^{-4}\right.$ to $3.0 \times 10^{-4} \mathrm{~mol} / \mathrm{g}$ ) obtained by the back-extraction method. ${ }^{7}$ In addition, the $\mathrm{CuCC}$ of the river water sample (TOC: $0.54 \mathrm{mg} / \mathrm{L}$ ), determined by the procedures described above, was $1.5 \times 10^{-4} \mathrm{~mol} / \mathrm{g}$, which is almost equal to that of commercial humic acid (Fig. 3).

probe and $\mathrm{CDL}$ voltages.

Plots: (upper) probe voltage; and (bottom) CDL voltage. Injected sample, $\left[\mathrm{Cu}^{2+}\right]=1.0 \times 10^{-5} \mathrm{M}$; carrier solution, $2.0 \times 10^{-5} \mathrm{M} \mathrm{BCS}$, $1.0 \times 10^{-4} \mathrm{M}$ ascorbic acid, and $1.0 \times 10^{-3} \mathrm{M} \mathrm{CH}_{3} \mathrm{COONH}_{4}$

of $\left[\mathrm{Cu}^{\mathrm{I}}(\mathrm{BCS})_{2}\right]^{3-}$ as a function of the probe voltage. In this case, the ion count increased as the probe voltage rose to the negative range. The maximum ion count was obtained by applying $-4.5 \mathrm{kV}$. The ion count then decreased upon the application of $-5 \mathrm{kV}$, possibly due to the fragmentation of $\mathrm{BCS}$, or the dissociation of copper from the $\mathrm{Cu}-\mathrm{BCS}$ complex. The optimal probe voltage was thus concluded to be $-4.5 \mathrm{kV}$.

The CDL is the section that removes the solvent contained in the fine charged particles that are generated by ESI. Applying a voltage to the CDL can also prevent the formation of larger droplets, which cause noise, bending the CDL. That is, the strength of the CDL voltage correlates to the sensitivity of an analyte peak. As shown in Fig. 2b, the ion count increased as the CDL voltage was increased to the negative range, and the

\section{Conclusions}

The FI-ESI-MS method developed in this study allowed the successful detection of $\mathrm{Cu}^{2+}$ with high selectivity and sensitivity, by complexation with BCS in the carrier. Our study demonstrates that this is useful as a simple method for the identification of $\mathrm{Cu}^{2+}$.

\section{Acknowledgements}

We deeply acknowledge Prof. Kin-Ichi Tsunoda (Gunma Univ.) and Assoc. Prof. Hiroki Hotta (Nara Univ. Educ.), who assisted in the use of the FI-ESI-MS apparatus. 


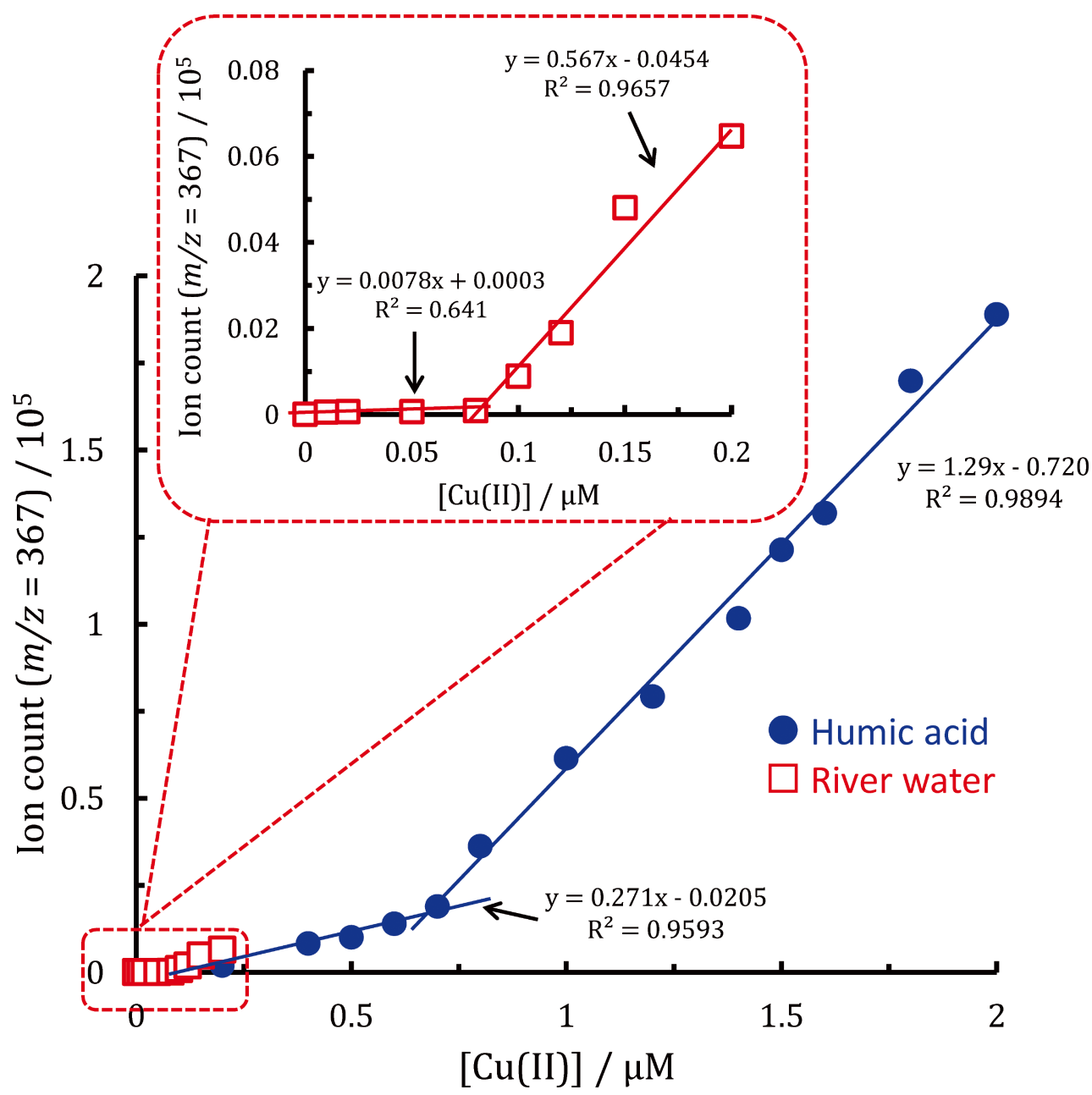

Fig. 3 Ion count of $\left[\mathrm{Cu}^{\mathrm{I}}(\mathrm{BCS})_{2}\right]^{3-}(\mathrm{m} / \mathrm{z}=367)$ as a function of the $\mathrm{Cu}^{2+}$ concentration added in the humic acid and river water sample solutions.

Injected sample, (humic acid) a mixture of $1.0 \times 10^{-7}$ to $2.0 \times 10^{-6} \mathrm{M} \mathrm{Cu}^{2+}$ and humic acid $(6.4 \mathrm{mg} / \mathrm{L}$ TOC); and (river water) a mixture of $1.0 \times 10^{-8}$ to $2.0 \times 10^{-7} \mathrm{M} \mathrm{Cu}^{2+}$ and river water $(0.54 \mathrm{mg} / \mathrm{L} \mathrm{TOC})$. Carrier solution, $6.0 \times 10^{-6} \mathrm{M} \mathrm{BCS}$ and $2.0 \times 10^{-5} \mathrm{M}$ ascorbic acid in $1.0 \times 10^{-3} \mathrm{M} \mathrm{CH}_{3} \mathrm{COONH}_{4}$.

\section{Supporting Information}

Chemical structures of the chelating agents used in this study are shown in Fig. S1. Mass spectra of Zn-chelating complexes are shown in Fig. S2 for comparison with Fig. 1. A calibration curve of the ion count of $\left[\mathrm{Cu}^{\mathrm{I}}(\mathrm{BCS})_{2}\right]^{3-}$ as a function of the copper(II) concentration is shown in Fig. S3. This material is available free of charge on the Web at http://www.jsac.or.jp/ analsci/.

\section{References}

1. K. Kumazawa, M. Yoshizawa, H.-B. Liu, Y. Kamikawa, M. Moriyama, T. Kato, and M. Fujita, Chem. Eur. J., 2005, 11, 2519.

2. H. Hotta, T. Mori, A. Takahashi, Y. Kogure, K. Johno, T. Umemura, and K. Tsunoda, Anal. Chem., 2009, 81, 6357.

3. S. Boija, A. Almesaker, E. Hedenström, D. Bylund, H. Edlund, and M. Norgren, J. Mass Spectrom., 2014, 49, 550.
4. K. Minakata, I. Yamagishi, H. Nozawa, K. Gonmori, K. Hasegawa, M. Suzuki, F. Horio, K. Watanabe, and O. Suzuki, Forensic Toxicol., 2012, 30, 149.

5. D. A. Barnett, R. Handy, and G. Horlick, "Elemental Speciation - New Approaches for Trace Element Analysis", ed. J. A. Caruso, K. L. Sutton, and K. L. Ackley, 2000, Chap. 12, Elsevier, Amsterdam, 384.

6. P. G. C. Campbell, "Interaction between trace metal and organisms; critique of the free-ion activity model", ed. A. Tessier and D. R. Turner, 1995, J. Wiley \& Sons, New York, 45.

7. H. Itabashi, Y. Kamata, D. Kawaguchi, and H. Kawamoto, Anal. Sci., 2003, 19, 1277.

8. E. Y. Jeong, M. B. Ansari, Y. H. Mo, and S. E. Park, J. Hazard. Mater, 2011, 185, 1311.

9. D. W. Dixon, A. F. Gill, and B. R. Sook, J. Porphyrins Phthalocyanines, 2004, 8, 1300.

10. B. Zak, J. S. Cohen, and L. A. Williams, Microchem. J., 1962, 6, 67.

11. T. Imamura and M. Fujimoto, Bull. Chem. Soc. Jpn., 1975, 48, 2971. 